the photomicrography. The histological sections were prepared by Mr. Hamilton and his staff.

\section{REFERENCES}

Bond, V. P., Cronkite, E. P., Fliedner, T. M., and Schork, P. (1958). Science, 128, 202.

Fliedner, T. M., Bond, V. P., Rubini, J. R., Brecher, G., and Quastler, H.' (1959). Ann.'N.Y. Acad. Sci., 77, 803.

Darmady, E. M., Dempster, W. J., and Stranack, F. (1955). J. Path. Bact., 70, 225 .

David, F. N., and Moore, P. G. (1954). Ann. Bot. (Lond.), 18, 47.

Dempster, W. J. (1953a). Brit. J. Surg., 40, 447.

(1953b). Brit. J. plast. Surg., 5, 228

(1953c). Arch. int. Pharmacodyn., 95, 253.

(1955). Brit. J. Urol., 27, 66

(1957). Introduction to Experimental Surgical Studies. Blackwell, Oxford.

- Calnan, J. S., and Kulatilake, A. E. (1963). Brit. med. J., 1,
Doniach, I., and Pelc, S. R. (1950). Brit. J. Radiol., 23, 184.

Fowler, R., and West, C. D. (1961). Aust. J. exp. Biol. med. Sci., 39, 537.

Galle, P., and Montera, H. de (1962). Rev. franc. Étude clin. biol., $7,40$.

Hamburger, J., Vaysse, J., Crosnier, J., Auvert, J., Lalanne, C. M., and Dormont, J. (1962). Ibid., 7, 20.

Hughes, W. L., Bond, V. P., Brecher, G., Cronkite, E. P., Painter, R. B., Quastler, H., and Sherman, F. G. (1958). Proc. nat. Acad. Sci. (Wash.), 44, 476

Nossal, G. J. V., and Mäkelä, O. (1961). J. exp. Med., 115, 209

Porter, K. A., and Calne, R. Y. (1960). Transplant. Bull., 26, 458.

Schooley, J. C., Bryant, B. S., and Kelly, Lola S. (1959). Kinetics of Cellular Proliferation, edited by F. Stohlman jun., p. 208 Grune and Stratton, New York.

Simonsen, M., Buemann, J., Gammeltoft, A., Jensen, F., and Jorgensen, K. (1953). Acta path. microbiol. scand., 32, 1.

Williamson, C. S. (1926). J. Urol., 16, 231

Wu, P. P. T., and Mann, F. C. (1934). Arch. Surg., 28, 889.

\title{
TIME OF ANTIGEN RELEASE FROM HOMOGRAFTS
}

BY

\section{W. J. DEMPSTER, F.R.C.S. \\ J. S. CALNAN, F.R.C.S. \\ A. E. KULATILAKE, F.R.C.S.}

Department of Surgery, Postgraduate Medical School of London

It is generally believed that, within a short period after grafting, antigen is in some way constantly transported from homografts to the reticulo-endothelial system of the host. We had no particular reason for challenging this concept until evidence apparently to the contrary gradually emerged from our work. The first doubts arose after the publication of work on kidney homotransplantation by Gordon and Richards (1957). These authors showed that when a second kidney was transplanted on the day that a first kidney had become anuric no accelerated rejection occurred. Indeed, the second behaved like a first kidney. It was not clear from their paper whether the second kidney had come from the same donor as the first; Gordon (personal communication, 1957) clarified the point that both first and second kidneys in each case had originated from the same donor. Evidence from previous work of our own indicated, in retrospect, that a first kidney removed on the fourth day while still fuctioning had no obvious sensitizing effect on a second kidney transplanted 4 to 10 days later (Dempster, 1955).

For several reasons we considered it opportune to gather some further information about the time at which antigen was released from skin and kidney homografts in dogs. In addition, it was considered worth while to gather some comparative data on skin grafts in rats and mice from which quantitative statistical analysis could be made.

\section{Materials and Methods}

Dogs.-Greyhounds of weight varying from 22 to $25 \mathrm{~kg}$. were used. Kidneys were transplanted by a technique previously described (Dempster, 1953a). Large ( 3 by 2 in. ; 7.5 by $5 \mathrm{~cm}$.) fitted full-thickness skin grafts were applied to the same recipient. Experiments done under such exacting conditions were difficult to achieve, and kidneys becoming anuric during week-ends were all lost to these experiments. The plan was: (1) To transplant second kidneys on the day that the first kidneys became anuric or oliguric. This was a repeat of the experiments reported by Gordon and Richards (1957). Four experiments were performed which exactly corresponded to conditions laid down.

(2) To apply skin homografts and to remove them while in an apparently healthy state on the eighth day. To wait 14 days and then apply a second skin homograft. Four experiments were performed.

Rats.-Forty-two Wistar rats of average weight 119.7 g. (S.D. 31.9) were used. The rats were obtained from two sources, and at neither was inbreeding practised. Designated Tuck's and St. Thomas's, they may be considered as not isogenic. Fitted full-thickness skin grafts were sutured to the facial layer of the back by the technique previously described (Calnan and Fry, 1962).

Mice.-Skin homografts were exchanged between nine mice of T.T. strain (white) and nine of C57 strain (black).

\section{Experimental Design}

Rats.-A random block design was executed in such a way that the assessment of viability of any particular skin graft was made without knowledge of its origin in order to remove any bias ("double - blind trial "). (1) Skin homografts of $1.5 \mathrm{~cm}$. diameter were exchanged between a pair of rats (Fig. 1) and at five, six, seven, or eight days later, while the grafts were still viable, returned

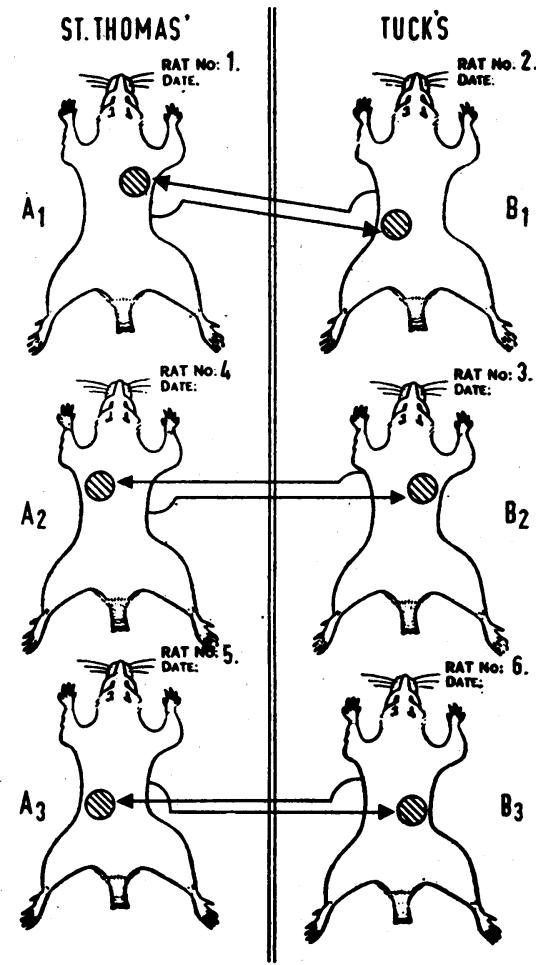

Fig. 1.-Random block experimental deFig. 1.
sign. First homografts (belly skin to defect on back) 
to their original donors. The experiment was conducted using three pairs of rats (a block) and repeated seven times (Fig. 2). (2) After an interval of 12 days each rat then received a second homograft from each of the three other rats of the opposite strain in its block (Fig. 3). Each rat of the six in the block now carried

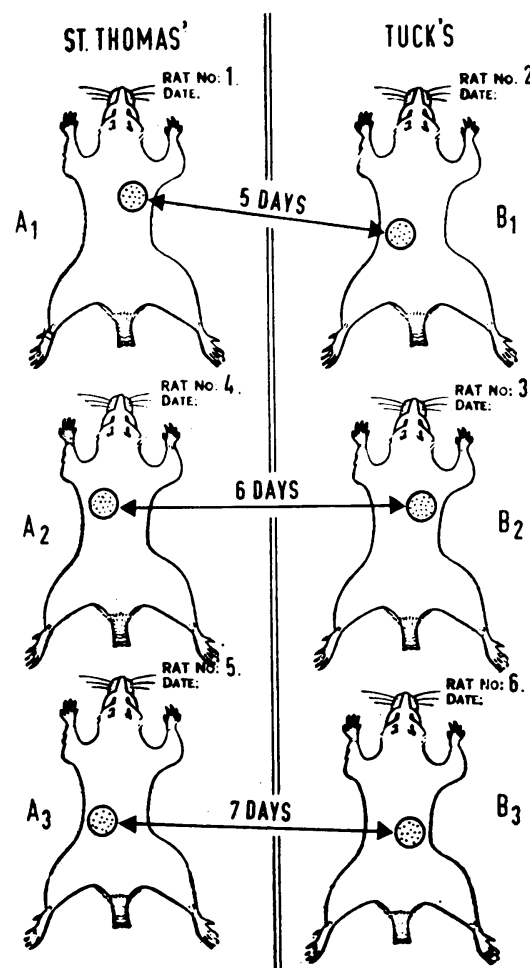

FIG. 2.-Random block experimental design. First homografts returned to original donors as homo-autografts.

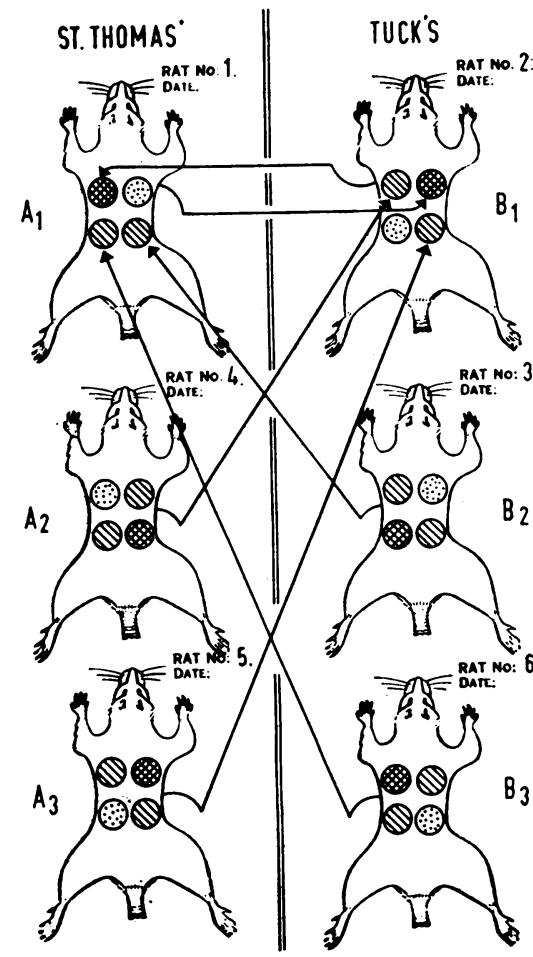

FIG. 3.-Random block experimental design. Second homograft from same donor and new homografts from new donors. four skin grafts of $1.5 \mathrm{~cm}$. diameter on its back. The origin of any one of the grafts was unknown to the examiner who inspected the grafts from the sixth day onwards. The time of rejection of a graft was assessed by naked-eye ins pection: a healthy skin graft being soft, pink, mobile ; a rejecting or rejected graft being pale, brown, crusted, dry or moist, firm or odorous.

Mice. - Each graft was $1.1 \mathrm{~mm}$. in diameter and the wet weight was $50 \mathrm{mg}$. The first skin homograft was removed while still a p p a r e n t 1 y healthy on the sixth day. After an interval of 14 days a second skin homograft was applied to the same recipients from the same donors. At the same time another $\mathrm{sk}$ i $\mathrm{n}$ homograft from a common donor of the opposite strain was applied to each recipient. The second skin homografts were examined at the fourth, sixth, seventh, a n d eighth days.

\section{Results}

Dogs.-Successive Kidney Trans p l a ntation: The four first kidneys survived $8,13,11$, and 7 days respectively. The second kidneys all survived at least four days, at which time they were removed. All showed the histological signs of first kidneys; none showed the characteristic damage of second kidneys, which are normally rejected within 24 hours when a time interval is allowed between the rejection of the first kidney and the transplantation of the second kidney from the same donor (Dempster, 1953a). Successive Skin-grafting: Each skin homograft removed on the eighth day appeared to be healthy (histology confirmed this). Second skin homografts applied after an interval of 14 days behaved as first grafts and survived 8 to 12 days. This survival period confirmed previous work involving first homografts (Dempster, 1952b). Usually the earliest signs of rejection of skin homografts-that is, thickening of texture or discoloration of discrete areas -are seen about the eighth day and definite death of skin occurs over the next four days.

Rats.-Three rats died during the experiment. The times of rejection of the 90 skin homografts available for assessment are recorded in Tables I and II. From these it will be noted that each rat should have been sensitized to its donor (by the homograft which was returned to its original donor at five, six, seven, or eight days) if immediate continuous release of antigen does,

TABLE I.-Rejection Times of Homografts (Rats)

\begin{tabular}{|c|c|c|c|c|}
\hline \multirow{3}{*}{$\begin{array}{c}\text { Homograft } \\
\text { Returned } \\
\text { to } \\
\text { Original } \\
\text { Donor } \\
\text { on Day: }\end{array}$} & \multicolumn{4}{|c|}{ Rejection Times: Mean (S.D.) in Days } \\
\hline & \multirow{2}{*}{$\begin{array}{c}\text { (Second* } \\
\text { Graft) } \\
\text { Original } \\
\text { Donor }\end{array}$} & \multicolumn{2}{|c|}{ First Graft } & \multirow{2}{*}{$\begin{array}{l}\text { Totals } \\
\text { Means }\end{array}$} \\
\hline & & $\begin{array}{c}\text { Donor } \\
\text { II }\end{array}$ & $\begin{array}{l}\text { Donor } \\
\text { III }\end{array}$ & \\
\hline $\begin{array}{l}5 \\
6 \\
7 \\
8\end{array}$ & $\begin{array}{r}8.2(1.92) \\
10.3(2.50) \\
9.7(2.55) \\
8.0(1.87)\end{array}$ & $\begin{array}{c}10 \cdot 0(3 \cdot 35) \\
9 \cdot 18(2 \cdot 11) \\
9 \cdot 82(2 \cdot 72) \\
8 \cdot 4(1 \cdot 34)\end{array}$ & $\begin{array}{c}13.6(5.60) \\
10 \cdot 44(3.23) \\
9 \cdot 55(2.79) \\
11.75(5 \cdot 51)\end{array}$ & $\begin{array}{r}10 \cdot 55 \\
9 \cdot 93 \\
9 \cdot 70 \\
9 \cdot 21\end{array}$ \\
\hline tals (me & $9 \cdot 36$ & $9 \cdot 42$ & $10 \cdot 92$ & \\
\hline
\end{tabular}

Standard error: for donors $=2 \cdot 124 ;$ for time $=1.736$

* First hor Third graft original donor: mean rejection time $(10$ rats $)=12$ days.

TABLE II.-Analysis of Variance: Rejection Times (in Days) of Various skin Homografts (Rats)

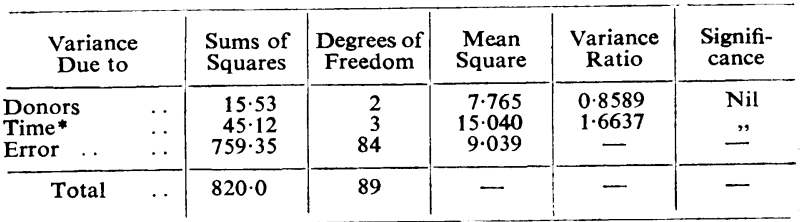

* "Time" refers to day on which first homograft was returned as an autograft to original donors.

in fact, occur. In practice the rejection time of all the skin homografts was similar. There was no accelerated rejection of second homografts in rats whose healthy first homografts had been returned successfully as autografts. Each of 10 rats was then challenged with a third skin homograft from its original donor 10 days after the complete rejection of the second homograft-that is, first homograft was removed prior to rejection. Each was also given a homograft from a common donor. The mean time of rejection was 12.0 days for both types of homografts. Thus no accelerated rejection of second homografts was found even when the recipient had rejected the first homograft.

Mice.-One C57 mouse died before the final inspection. There was no statistical difference between the rejection times of the survival of second skin grafts from either the original donor or the common donor (Table 
III). No evidence of an accelerated rejection of second skin homografts was observed.

TABLE III.-Skin Homografts Exchanged Between Two Pure Strains of Mice. (T.T. Strain and C57)

\begin{tabular}{|c|c|}
\hline Skin Homograft & $\begin{array}{c}\text { Mean Time of } \\
\text { Rejection (Days) }\end{array}$ \\
\hline $\begin{array}{l}\text { First graft was removed on } 6 \text { th day while apparently } \\
\text { healthy } \\
\text { Second graft applied } 14 \text { days after removal of first } \\
\text { graft on } 6 \text { th day (17 grafts) } \\
\text { Graft from common donor of pure strain applied at } \\
\text { same time as second graft from same donor (18 } \\
\text { grafts) } \quad \text {.. . . . . . . . }\end{array}$ & $\begin{array}{c}- \\
7 \cdot 9(\text { S.D. } 1 \cdot 11) \\
7 \cdot 8(\text { S.D. } 1 \cdot 23)\end{array}$ \\
\hline
\end{tabular}

\section{Discussion}

Briefly the facts involving skin and kidney homografts in dogs can be summarized as follows: (1) If an interval of some days was allowed between the onset of anuria and the removal of first kidneys and the transplantation of second kidneys, a very rapid and histologically characteristic rejection of second homotransplanted kidneys occurred (Dempster, 1953a). (2) If no interval was allowed between the onset of anuria and the removal of the first kidney and the transplantation of the second kidney, a history characteristic of a first homotransplanted kidney was found (Gordon and Richards, 1957) ; this is confirmed by our own data presented here. (3) If a first kidney was removed while functioning well for four days and after an interval of 4 to 10 days a second kidney was transplanted, it behaved as a first 1omotransplanted kidney (Dempster, 1955). (4) If an rrthotopic skin homograft was removed on the eighth day while in an apparently healthy state and if after an interval of 14 days a second skin homograft was applied, a life-history characteristic of a first skin homograft occurred. (5) If a first skin homograft was allowed to be rejected and after an interval of a few days a second skin homograft was applied, rejection of the latter occurred within six days (Dempster, 1953b).

The data on the rat can be summarized as follows: (1) If a first skin homograft was removed at any time from one to eight days after its application and before signs of obvious rejection were seen, then a second skin homograft (applied after an interval of 12 days) survived for as long as a first skin homograft. (2) If a first skin homograft was allowed to be rejected (survival time about 10 days) and after an interval of 10 days a second skin homograft from the same donor was applied, it also survived for as long as the first. Even third skin homografts survived for as long as first skin homografts.

From our experience in assessing day-to-day appearances of skin autografts and homografts in rats, we would not be inclined to accept results which were not arrived at by a double-blind trial test system used in these experiments. We would not accept results based on lack of bleeding on removing a skin homograft as an indicator of accelerated rejection, because it is not reliable and bias can be introduced.

So far as the results of the initial rat experiments are concerned, no evidence of sensitization of the host was found. However, since an accelerated rejection of second homografts was not encountered we cannot correlate, at this juncture, the rat and dog data. We can offer no explanation for the failure to elicit, in rats, an accelerated rejection of second homografts. We presume there must be a species difference here and certainly did not expect such a result.
So far as the results in dogs and mice are concerned, there is no evidence of continuous or intermittent release of antigen during the functioning phase of the first homografts. It would appear that graft transplantation antigen is not released until the rejection process is well under way and that time thereafter is required before a characteristic accelerated reaction can be elicited. It is conceivable, however, that the sensitizing factor is altered biological material and that natural transplantation antigen does not exist. The breakdown of tissue cells may produce an adjuvant effect similar to Freund's adjuvant as a prerequisite in the production of autoimmunity (or more accurately auto-antigenation). If this is so it might have some influence on the tactics to be employed in prolonging survival of organ transplants in larger mammals, including man.

\section{Summary}

The experiments reported here were designed to test the assumption that antigen is continuously or intermittently released from a homograft soon after its application to its host. Skin homografts were removed at a point just prior to the anticipated time of rejection, dogs at the eighth day and rats and mice at the sixth day. After an interval of 10 to 14 days a second challenge of skin from the same donor was applied. It was found that the second skin homograft survived for as long as the first normally does. This result was clear-cut in dogs and mice. The rats showed a difference in that it was not possible to demonstrate a typical second graft reaction-that is, an accelerated rejection. We accept that an accelerated second graft rejection can be demonstrated in mice.

Other experiments involved the homotransplantation of second kidneys on the very day that the first kidneys became oliguric. These experiments indicated that second kidneys, under the defined conditions, did not undergo an accelerated rejection but survived as first kidneys until they were removed.

Since we were not able to demonstrate that under these given conditions host animals became sensitized by a homograft removed just prior to anticipated rejection we tentatively arrive at the conclusion that natural tissue transplantation antigen, as such, does not exist. Natural tissue in the process of disruption and liquefaction, as a result of rejection, becomes altered so as to be antigenic. This concept would throw more of the responsibility for rejection on processes within the first homograft itself as a reaction against unknown factors in the host.

The expenses involved in these experiments were defrayed by grants to two of us (W. J. D. and J.S. C.) from the Medical Research Council. We are indebted to Miss Norma Hirst and Miss Veronica Hanly for technical assistance.

\section{REFERENCES}

Calnan, J., and Fry, H. (1962). Brit. J. plast. Surg., 15, 155 Dempster, W. J. (1953a). Brit. J. Surg., 40, 447. (1953b). Brit. J. plast. Surg., 5, 228. - (1955). Brit. J. Urol., 27, 66. Gordon, L. A., and Richards, V. (1957). Surgery, 42, 163.

The British Epilepsy Association, together with epilepsy associations in Sweden and Holland, has decided to support the formation of an International Bureau for the exchange of information about epilepsy. In furtherance of this proposal an official of the British Epilepsy Association is to visit representatives of the American Epilepsy Federation in Boston. 